\title{
Printed Spacecraft Separation System
}

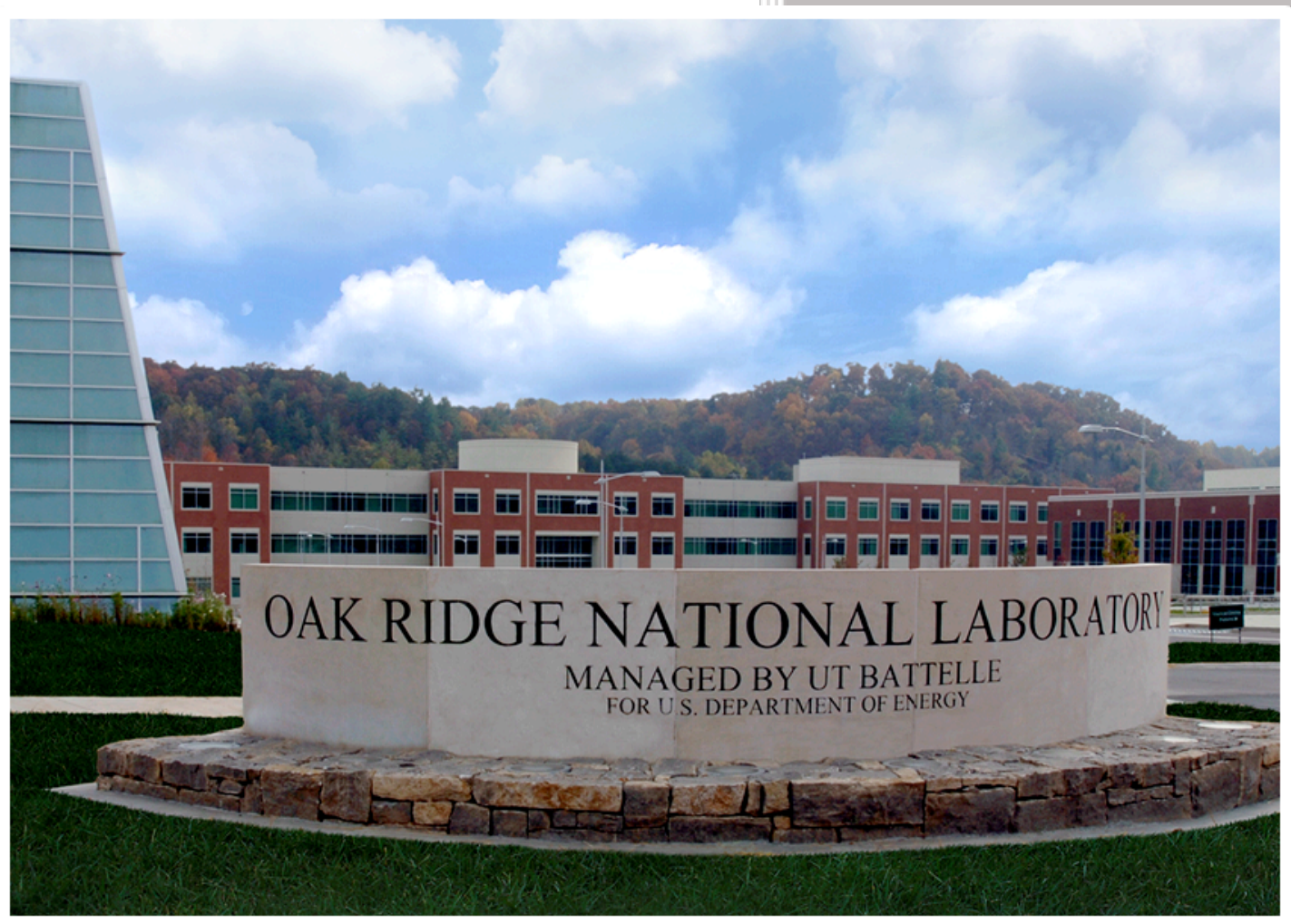

Ryan Dehoff

September 13, 2016

CRADA FINAL REPORT

NFE-14-05108

Approved for Public Release.

Distribution is Unlimited. 


\title{
DOCUMENT AVAILABILITY
}

Reports produced after January 1, 1996, are generally available free via US Department of Energy (DOE) SciTech Connect.

Website http://www.osti.gov/scitech/

Reports produced before January 1, 1996, may be purchased by members of the public from the following source:

\author{
National Technical Information Service \\ 5285 Port Royal Road \\ Springfield, VA 22161 \\ Telephone 703-605-6000 (1-800-553-6847) \\ TDD 703-487-4639 \\ Fax 703-605-6900 \\ E-mail info@ntis.gov \\ Website http://www.ntis.gov/help/ordermethods.aspx
}

Reports are available to DOE employees, DOE contractors, Energy Technology Data Exchange representatives, and International Nuclear Information System representatives from the following source:

Office of Scientific and Technical Information

PO Box 62

Oak Ridge, TN 37831

Telephone 865-576-8401

Fax 865-576-5728

E-mail reports@osti.gov

Website http://www.osti.gov/contact.html

This report was prepared as an account of work sponsored by an agency of the United States Government. Neither the United States Government nor any agency thereof, nor any of their employees, makes any warranty, express or implied, or assumes any legal liability or responsibility for the accuracy, completeness, or usefulness of any information, apparatus, product, or process disclosed, or represents that its use would not infringe privately owned rights. Reference herein to any specific commercial product, process, or service by trade name, trademark, manufacturer, or otherwise, does not necessarily constitute or imply its endorsement, recommendation, or favoring by the United States Government or any agency thereof. The views and opinions of authors expressed herein do not necessarily state or reflect those of the United States Government or any agency thereof. 
ORNL/TM-2016/533

CRADA/ NFE-14-05108

Materials Science and Technology Division

Advanced Manufacturing Office

\title{
Printed Spacecraft Separation System
}

\author{
Authors \\ Ryan Dehoff \\ Walter Holemans
}

Date Published:

September 13, 2016

\footnotetext{
Prepared by

OAK RIDGE NATIONAL LABORATORY

Oak Ridge, Tennessee 37831-6283

managed by

UT-BATTELLE, LLC

for the

US DEPARTMENT OF ENERGY

under contract DE-AC05-00OR22725
}

Approved For Public Release 


\section{CONTENTS}

CONTENTS $\ldots \ldots \ldots \ldots \ldots \ldots \ldots \ldots$
LIST OF FIGURES $\ldots \ldots \ldots \ldots \ldots \ldots$




\section{LIST OF FIGURES}

Fig. 1. A printed titanium design is derived from the conventional machined aluminum design.

Fig. 2. The housings and brackets for the separation switch, separation electrical connector, spring and compression features are all printed in, greatly reducing cost of parts and time to assemble. The springs are shown in their deployed state. Another part is required to hold the spring in a state of compression.

Fig. 3. Deflection of the various printed components with the linear response region highlighted in

green. 


\section{ACKNOWLEDGEMENTS}

This CRADA NFE-14-05108 was conducted as a Technical Collaboration project within the Oak Ridge National Laboratory (ORNL) Manufacturing Demonstration Facility (MDF) sponsored by the US Department of Energy Advanced Manufacturing Office (CPS Agreement Number 24761).

Opportunities for MDF technical collaborations are listed in the announcement "Manufacturing Demonstration Facility Technology Collaborations for US Manufacturers in Advanced

Manufacturing and Materials Technologies" posted at http://web.ornl.gov/sci/manufacturing/docs/FBO-ORNL-MDF-2013-2.pdf. The goal of technical collaborations is to engage industry partners to participate in short-term, collaborative projects within the Manufacturing Demonstration Facility (MDF) to assess applicability and of new energy efficient manufacturing technologies. Research sponsored by the U.S. Department of Energy, Office of Energy Efficiency and Renewable Energy, Advanced Manufacturing Office, under contract DE-AC0500OR22725 with UT-Battelle, LLC. 



\begin{abstract}
In this project Planetary Systems Corporation proposed utilizing additive manufacturing (3D printing) to manufacture a titanium spacecraft separation system for commercial and US government customers to realize a $90 \%$ reduction in the cost and energy. These savings were demonstrated via "printing-in" many of the parts and sub-assemblies into one part, thus greatly reducing the labor associated with design, procurement, assembly and calibration of mechanisms. Planetary Systems Corporation redesigned several of the components of the separation system based on additive manufacturing principles including geometric flexibility and the ability to fabricate complex designs, ability to combine multiple parts of an assembly into a single component, and the ability to optimize design for specific mechanical property targets. Shock absorption was specifically targeted and requirements were established to attenuate damage to the Lightband system from shock of initiation. Planetary Systems Corporation redesigned components based on these requirements and sent the designs to Oak Ridge National Laboratory to be printed. ORNL printed the parts using the Arcam electron beam melting technology based on the desire for the parts to be fabricated from Ti-6Al-4V based on the weight and mechanical performance of the material. A second set of components was fabricated from stainless steel material on the Renishaw laser powder bed technology due to the improved geometric accuracy, surface finish, and wear resistance of the material. Planetary Systems Corporation evaluated these components and determined that $3 \mathrm{D}$ printing is potentially a viable method for achieving significant cost and savings metrics.
\end{abstract}

\title{
1. PRINTED SPACECRAFT SEPARATION SYSTEM
}

This phase 1 technical collaboration project (MDF-TC-2014-035) was begun on May 6, 2014 and was completed on September 13, 2016. The collaboration partner Planetary Systems Corporation is a small business. The results indicate 3D printing technology can reduce cost, weight and time on printed space components though expert design optimization.

\subsection{BACKGROUND}

Planetary Systems Corporations builds the ideal separation systems to ensure reliability and optimized performance with a history of innovation followed by intense and rewarding engineering to prove reliability. This has led to an excellent flight heritage for over 15 years for various launch vehicles including the Delta IV, the Atlas V 401, and the Falcon 9 among many others. Products such as the Mark II Motorized Lightband space vehicle separation system that have been in production for many years, are based on conventional manufacturing and design processes. Although much of the structure is made of aluminum to minimize weight, advanced manufacturing technologies such as 3D printing can significantly decrease the weight of the system. Because these systems are launched into orbit, weight is a critical factor for both performance and decreasing the overall energy consumption of the launch. In addition to weight savings, additive manufacturing offers the ability to greatly reduce the complexity of the individual system components and can dramatically reduce assembly and manufacturing time.

In this project Planetary Systems Corporation (PSC) proposed an additively manufactured or "printed" titanium spacecraft separation system to realize a $90 \%$ reduction in the cost and energy to procure a separation systems for commercial and US government customers. These savings are 
attained by "printing-in" many of the parts and sub-assemblies into one part, thus greatly reducing the labor associated with design, procurement, assembly and calibration of mechanisms.
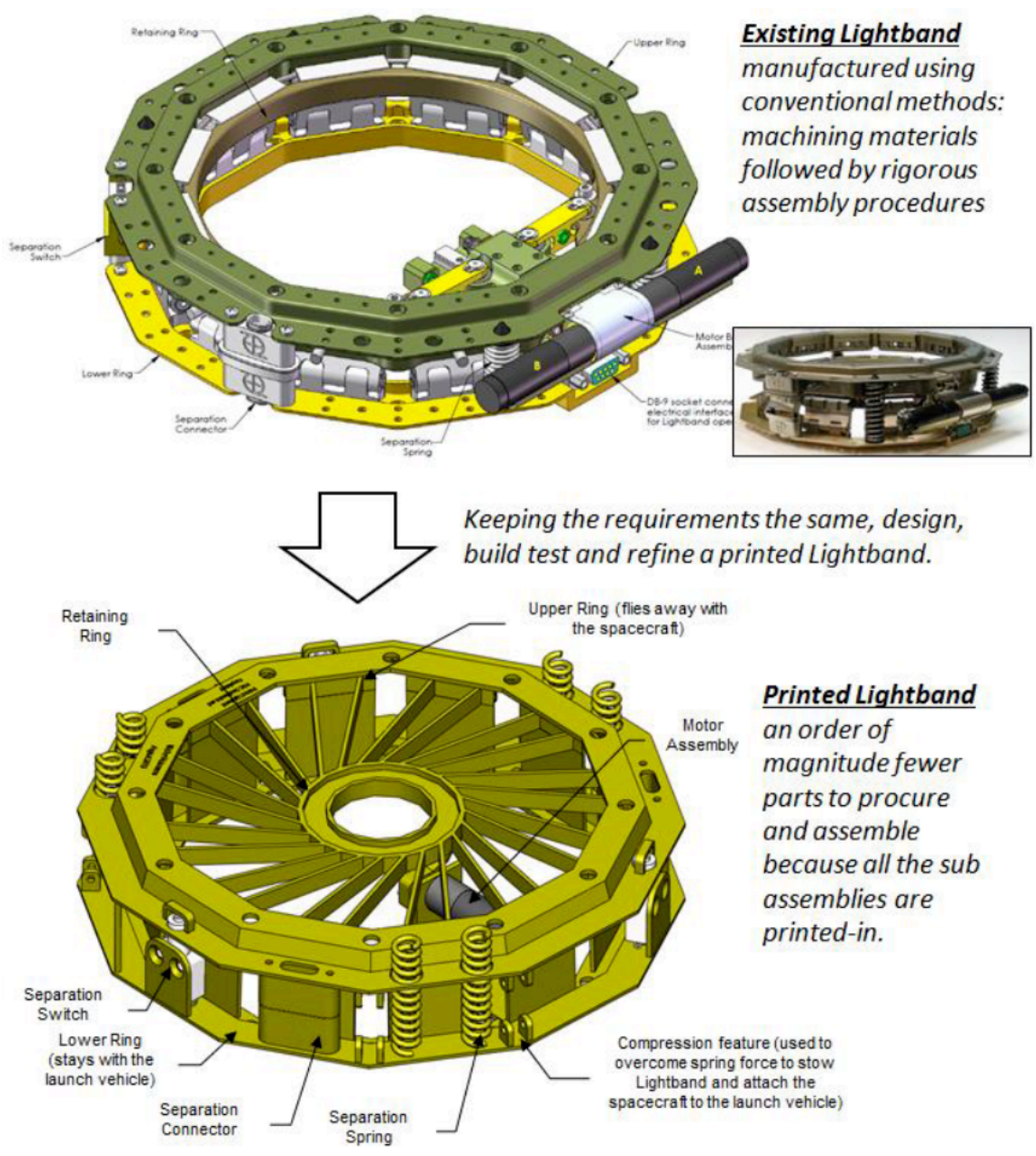

Fig. 1. A printed titanium design is derived from the conventional machined aluminum design.
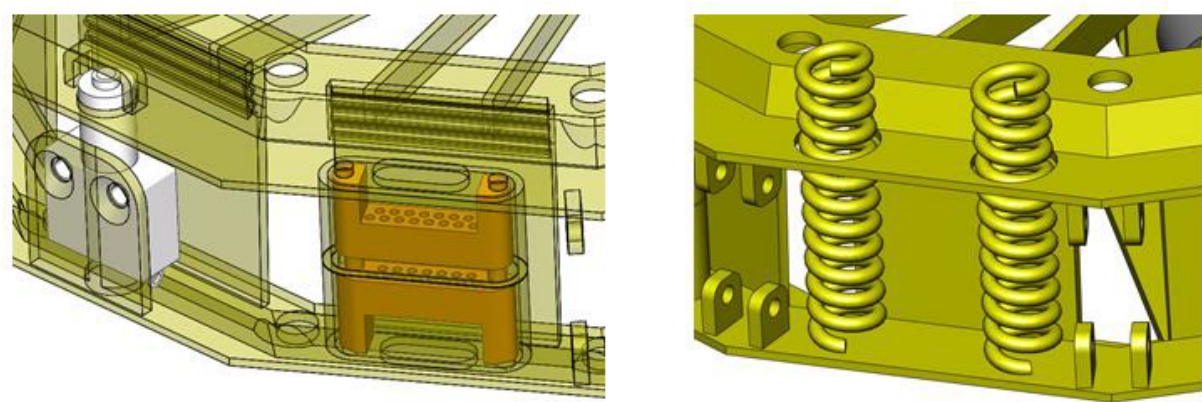

Fig. 2. The housings and brackets for the separation switch, separation electrical connector, spring and compression features are all printed in, greatly reducing cost of parts and time to assemble. The springs are shown in their deployed state. Another part is required to hold the spring in a state of compression. 


\subsection{TECHNICAL RESULTS}

Planetary Systems Corporation examined their existing separation system and determined the ideal components that could benefit from design optimization through additive manufacturing technologies. The determination made was to outline the shock absorption requirements of the system. Planetary Systems Corporation determined there are three main requirement functions for the components; attenuate damage to the Lightband from shock of initiation, attenuate shock to the adjoining structures, and to attenuate leaf and retaining ring motions that may produce substantial variation in tip-off and Delta $V$. The environment extremes in order to qualify the system was determined to be a preload of 500 to $1,500 \mathrm{lbf}$, an operating temperature of -40 to +90 degrees Celsius, and the quantity of Lightband operations to be 10,000 separations. For the adjoining structures, the attenuation shock was required to be less than the MkII shock. The design also required that the system would not seize, allowing the retaining ring to expand and not allowing the leaves to rotate towards the stowed condition. This is required in order for the system to function properly in the service condition.

Planetary Systems Corporation determined the ideal solution to be a tapered friction brake flexure. The design of the flexure was such that it allowed for arrest of the initiator, prevented recoil which would reduce tip-off and prevent damage to the system. The primary material selected was Ti$6 \mathrm{Al}-4 \mathrm{~V}$ in the as-deposited surface condition. No post machining or surface processing was required for the design of the components. Planetary Systems Corporation examined several different designs and each design was examined using finite element analysis software in order to predict the performance of the parts under mechanical loading. The stiffness was varied in several of the samples as part of the optimization process.

The designs determined by Planetary Systems Corporation were sent to Oak Ridge National Laboratory (ORNL) and were then printed using the Arcam Q10 electron beam melting technology at the ORNL Manufacturing Demonstration Facility (MDF). The powder utilized for fabrication of the parts was plasma sherardized Ti-6Al-4V powder from Tekna. The powder had been utilized previously for a single build. A total of three attempts were made on the Arcam process to fabricate the parts due to variations in software and issues with the filament. Two of the builds that failed due to challenges associated with delamination between the layers of the build and also showed some swelling of the parts due to the geometry of the build layout. The delamination is speculated to result from undulations in the thickness of the powder bed after the raking process leading to the melted region in the new layer not fully melting into the layer below. This can lead to large areas where there is no contact between subsequent layers. The propensity for delamination can be magnified for different geometries, especially those that are close our outside the acceptable geometries for the process algorithm that determines the beam current and melting speed. Therefore, additional tensile bars and blocks of material were inserted into the build chamber in order to achieve the ideal energy input into the system over the duration of the build, limit the geometric inaccuracies, and eliminate delamination.

Based on the reconfiguration of parts and tensile geometries in the system a successful build was deposited despite the parts being close to the minimum scale and resolution for components fabricated via the electron beam melting process. The parts were fabricated using software version 5.0.60 with preheat theme 5.0.56, melt theme 5.0.56, and a wafer support theme 5.0.56. Both log file data and in-situ porosity imaging was conducted for each build on the system. Porosity level within the parts appeared to be in an acceptable range for proper function of the parts. However, no mechanical property data was acquired for components fabricated although it is expected that the Ti6Al-4V material will perform similar to previously tested material from the Arcam Q10 system. Parts were then sent to Planetary Systems Corporation for testing of the components and comparison to the 
predictive modeling performed during the design phase.

Two key mechanical property requirements were examined at Planetary Systems Corporation in the printed components including measuring the actual stiffness (for comparison to the analytical stiffness) and the energy absorption of the designs. Various tests were performed on the printed components including geometric accuracy of the components, stiffness testing, energy abortion, and shock testing. Table 1 shows the stiffness measurements for the 6 different components tested ( 3 in the $\mathrm{X}$ and 3 in the $\mathrm{X}-\mathrm{Y}$ direction). The results indicate that the modulus of the printed titanium components, in small thickness, has a substantially lower modulus than the machined titanium. Although the modulus is different than conventional manufacturing processes, it appeared to be constant within the different samples. This will allow for a simple design change in the final component in order to account for the difference. Figure 3 is a plot of load versus deflection with the liner response region highlighted in green.

\begin{tabular}{|c|c|c|c|c|c|c|}
\cline { 2 - 7 } \multicolumn{1}{c|}{$\begin{array}{c}\text { Load (F100) } \\
{[\text { Lbf] }}\end{array}$} & \multicolumn{7}{|c|}{ Print Direction X } & \multicolumn{2}{c|}{ X-Y print Direction } \\
\cline { 2 - 7 } & Nom & +0.004 & +0.008 & Nom & +0.004 & +0.008 \\
\hline 0 & 0.0000 & 0.0000 & 0.0000 & 0.0000 & 0.0000 & 0.0000 \\
\hline 10 & 0.0024 & 0.0028 & 0.0022 & 0.0024 & 0.0019 & 0.0060 \\
\hline 20 & 0.0057 & 0.0061 & 0.0052 & 0.0056 & 0.0051 & 0.0120 \\
\hline 30 & 0.0096 & 0.0096 & 0.0080 & 0.0103 & 0.0086 & 0.0134 \\
\hline 40 & 0.0132 & 0.0127 & 0.0110 & 0.0133 & 0.0127 & 0.0170 \\
\hline 50 & 0.0162 & 0.0155 & 0.0136 & 0.0169 & 0.0155 & 0.0191 \\
\hline 60 & 0.0197 & 0.0180 & 0.0168 & 0.0200 & 0.0168 & 0.0214 \\
\hline 70 & 0.0215 & 0.0187 & 0.0187 & 0.0210 & 0.0180 & 0.0237 \\
\hline 80 & 0.0218 & 0.0191 & 0.0193 & 0.0221 & 0.0190 & 0.0250 \\
\hline 90 & 0.0221 & 0.0192 & 0.0195 & 0.0220 & 0.0212 & 0.0261 \\
\hline 100 & 0.0223 & 0.0192 & 0.0199 & 0.0226 & 0.0222 & 0.0270 \\
\hline & & & & & & \\
\hline & & & & & & \\
\hline Kact [Lbf/in] & 2,839 & 3,187 & 3,544 & 2,688 & 2,819 & 3,914 \\
\hline Kest [Lbf/in] & 4,545 & & & 4,545 & & \\
\hline Kact/Kest [-] & 0.62 & & & 0.59 & & \\
\hline & & & & & & \\
\hline Kdes [Lbf/in] & 3,825 & 3,825 & 3,825 & 3,825 & 3,825 & 3,825 \\
\hline Kact/Kdes [-] & 0.74 & 0.83 & 0.93 & 0.70 & 0.74 & 1.02 \\
\hline
\end{tabular}

Table 1: Stiffness values for different geometries and orientation in the printing chamber. 


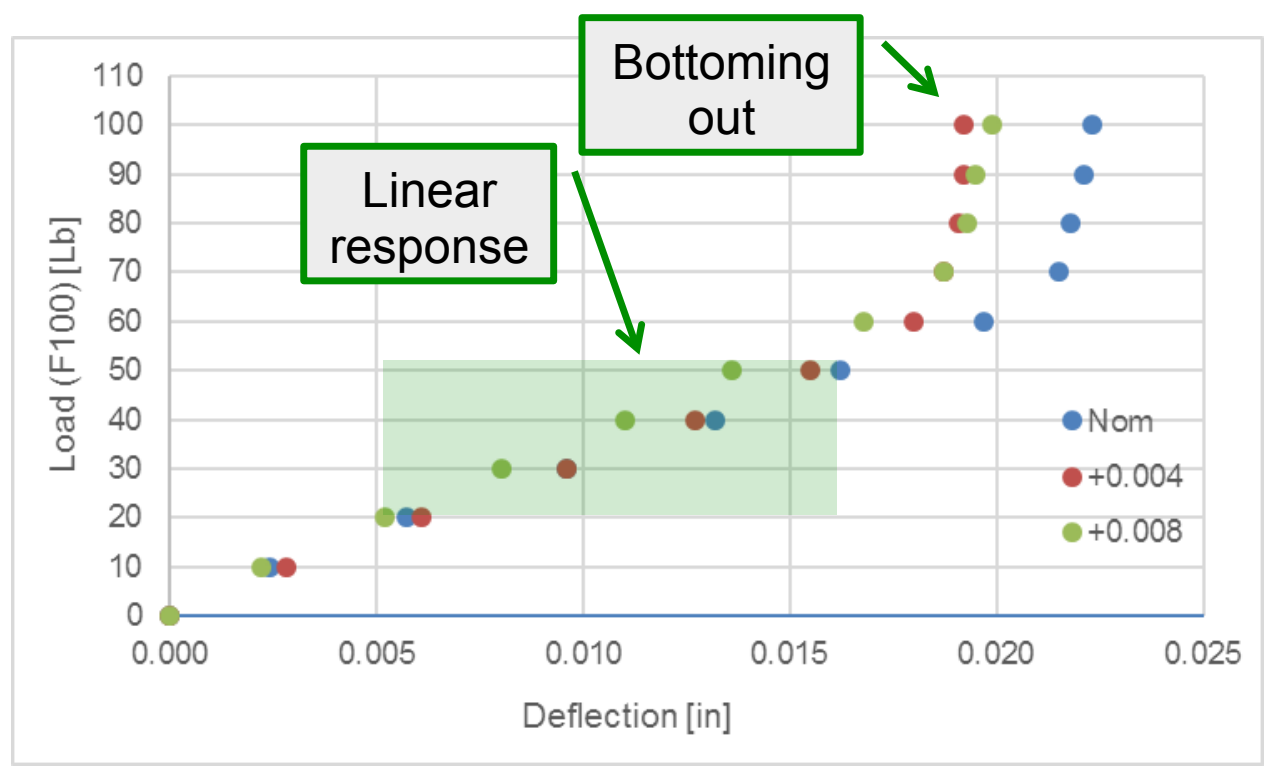

Fig. 3. Deflection of the various printed components with the linear response region highlighted in green.

Although the electron beam deposited printed components were within several tens of thousandths from the nominal geometry, greater precision is required in order to prevent over travel of the system. If this precision requirement is not met, the sliding bracket geometry will exceed the allowable limits and cause failure. It may be reasonable to machine the surface of the components in order to achieve the desired resolution, however this is expected to add cost to the manufacturing process. Because estimates for fabrication of these components through an external vendor were higher than expected, adding additional cost with machining is not ideal. An additional challenge that was encountered was the surface roughness produced in the as deposited condition is not adequate as titanium alloys have a tendency to gall, increasing the coefficient of friction. It is expected that this would lead to unacceptable wear rates and limit the total number of initiations to $\sim 1,000$ which is significantly lower than the target of 10,000 .

Based on the galling and wear resistance requirements to meet 10,000 initiations and the precision requirements encountered in the first set of components fabricated using the Arcam technology, a set of parts were fabricated from stainless steel on the Renishaw laser powder bed system. These parts appear to meet the galling requirements. However, the issue of residual stress and distortion with laser powder bed technology may be a challenge for the precision of the components. There are several geometric features that could benefit from a redesign tailored for the Renishaw system, as there is often a difference in in the ability to print between electron beam and laser technology.

\subsection{IMPACTS}

Printed spacecraft mechanisms are directly and presently applicable to US Department of Defense DoD missions that require small and lightweight separation systems such as the Missile Defense Agency (MDA), the National Reconnaissance Office (NRO) and NASA interplanetary missions. Commercially, US firms such as Space Flight Services and SpaceX greatly benefit by the reduced cost of separation systems and shorter product lead times. Those two firms are at the forefront of revolutionizing space access by replacing methods and materials that have traditionally kept costs very high. They are also PSC's customers for existing Lightbands. As such these firms would be first adopters of this new technology enabling the most rapid adoption and competitive gain of by the rest 
of the US aerospace industry. Printed Separation systems ought to realize a materials cost reduction of $28 \%$ and a $90 \%$ reduction in labor for assembly.

\subsection{CONCLUSIONS}

The research conducted under this agreement resulted in a new design for various components in their current separation system based around additive manufacturing design concepts. Components were tested for component stiffness, energy absorption, shock behavior, and geometric accuracy and surface finish. The components were fabricated from Ti-6Al-4V at the Manufacturing Demonstration Facility utilizing the Arcam Q10 electron beam melting technology. The components fabricated had geometric features and desired accuracy requirements nearing the limits of the EBM technology. Parts tested at Planetary Systems Corporation for the aforementioned features demonstrated the components successfully met the requirements from the design perspective for energy absorption, stiffness, and shock behavior. However, the geometric accuracy requirements could not be met by the technology and improvements were needed in both geometric accuracy and surface finish in order to implement the technology into current production cycles. Both surface finish and accuracy could be improved through post processing such as machining, however due to the high cost associated with component manufacturing this does not appear to be a feasible solution.

Components fabricated on the Renishaw laser powder bed technology using stainless steel materials demonstrated the potential to meet the surface finish requirements for the components, however geometric accuracy must be improved. The geometric accuracy is limited through residual stress and distortion associated with the process. Additional work would be needed in a Phase 2 effort in order to fabricate parts and show the ability to reduce the complexity of mechanisms by about $90 \%$ by greatly reducing the number of parts in an assembly. This is analogous to the way printed wiring boards unburden electrical engineers of the labor to discretely wire each electrical junction. It can also lower the overall cost of features by $28 \%$ and shortens development and delivery time by $50 \%$. In short, mechanism can be lighter, higher performance, smaller, cheaper and procured more rapidly. The utility of printing can be illustrated by comparing a traditional eight inch diameter Lightband to a proposed printed Lightband.

Planetary Systems Corporation, through its work with ORNL, now understands that printed metal can revolutionize spacecraft mechanisms because it can simultaneously lower costs and increase performance (like lower weight). We look forward continuing the iterative-design-build-test method we have been using to date. PSC will likely orbit a printed metal design on our new separation system in 2017. We believe that other high value aerospace vehicles will benefit similarly. This includes aircraft, helicopter and missile mechanisms.

\section{PARTNER BACKGROUND}

Planetary Systems Corporation (PSC) designs and produces mechanisms that separate space vehicles from launch vehicles. PSC is a small business located in Silver Spring, MD and was founded 15 years ago. Our products have flown more than 40 times on all US launch vehicles without any failure or anomaly. PSC products include Lightband separation system for larger spacecraft and Canisterized Satellite Dispenser (CSD) used to separate Cubesats. 